
\section{Biology and the behaviour of man}

\author{
John Maynard Smith
}

Vaulting Ambition: Sociobiology and the Quest for Human Nature. By Philip Kitcher.

MIT Press: 1985. Pp.447. \$24.95, £24.95.

Do WE really need another critique of sociobiology? In general, probably not. but perhaps we need this one. Kitcher, like everyone else, approaches the problem with prejudices, but he tries harder and more successfully than most to rise above them. Prejudices are inevitable. It is natural for geneticists and evolutionary biologists to hope that their disciplines will throw new light on the human condition. and equally natural for social scientists to resist the threatened takeover. More important for many of us. previous efforts to apply biology to human affairs have too often ended up as justifications for racial, sexual and class inequalities. Kitcher, who grew up in England, has not forgotten that, in the post-War years, schoolchildren were divided at the age of eleven into sheep and goats, and that this division was justified by the leading experimental psychologists of the day. He and I share this experience - he as a tested child and I as a parent of tested children. It has left us cautious about proposals to use biological theory to plan human institutions.

Kitcher, then, is unsympathetic to the claim that evolutionary biology can guide

\section{... what we now need in sociobiology is a more cautious analysis of the data . . .}

political judgement, and I suspect he was unsympathetic before he started work on this book. Unlike some other authors, however, he has undertaken a genuine study. He does understand the ideas he is criticizing. He has the biological knowledge to evaluate the evolutionary background to sociobiology, and the mathematical ability to analyse the claims made for it. Above all, he presents sociobiology in its strongest and most coherent form, and avoids the easy option of attacking only its more idiotic manifestations.

$\mathrm{He}$ distinguishes sharply between the attempt to understand the evolution of social behaviour in animals, and attempts to understand man. He is sympathetic to the former enterprise. Correctly, he points out that there is no special underlying theory: "There is no autonomous theory of the evolution of behaviour. There is only the general theory of evolution". It may be that interactions between relatives, and frequency-dependent fitnesses, were more important in the evolution of the behaviour of birds than in the evolution of their wings, but they are not peculiar to behavioural evolution: kin selection and game theory are just as relevant to plant evolution.
There is, of course, good and bad work in animal sociobiology, and Kitcher gives examples of both. The bad, he points out, has two characteristics: data are quoted as supporting some specific hypothesis. without considering alternatives, and the hypotheses themselves are modified after the fact until data and predictions are brought into line. However, his chapter "Dr Pangloss's Last Hurrah", which takes issue with the "adaptationist program", seems to me only partly correct. He presents two genetical reasons for not expecting perfect adaptation. The first is that there are genetic systems, even with constant fitnesses, in which selection will not fix the fittest genotype. The simplest is that of heterozygous advantage: if $\mathrm{Aa}$ is fitter than AA or aa, selection cannot produce a population consisting entirely of Aa individuals. This is of course true, but is it interesting? If we want to understand why some species does not have the phenotype predicted by theory, this kind of genetic detail is rather unlikely to be the reason. Suppose, for example, we are interested in the shape of vertebrate wings. Aerodynamic theory shows that the optimal shape is usually elliptical. Pterodactyls, however, never had elliptical wings, but no one would explain this by suggesting that, perhaps, only heterozygotes had elliptical wings. The true explanation has to do with the way in which pterodactyl wings were made. Of course, this would be reflected in the absence of certain kinds of heritable variability, but that is not a useful way of thinking about the problem. For phenotypes of the complexity typically discussed by sociobiologists, it is usually better to think at the level genetics.

All the same, there will be cases in which this kind of genetic constraint will be relevant. The second kind of genetic constraint discussed by Kitcher, however, seems to me to be a misunderstanding. $\mathrm{He}$ points out that when fitnesses are frequency-dependent, the mean fitness of a population may decrease under selection. Therefore, he says, "proponents of certain design would maximize mean fitness may not automatically assume that selection can produce this design". Now, as Kitcher understands very well, a major that selection acting at the level of the individual does not necessarily lead to the evolution of characteristics optimal for the population. One of the main reasons for of development and physiology than of optimization analyses who show that a thrust of sociobiology has been to show this is that fitnesses are frequencydependent. Evolutionary game theory was developed specifically to analyse such cases. It is not sociobiologists who suppose that selection "maximizes [population] mean fitness". It is ironic that the phrase "Pangloss's theorem" was first used in the debate about evolution (in print. I think, by myself, but borrowed from a remark of Haldane's), not as a criticism of adaptive explanations, but specifically as a criticism of "groupselectionist", mean-fitness-maximizing arguments.

Thus I think that Kitcher is unfair to sociobiologists when he introduces the argument from frequency-dependence. However, it is a rare slip: in general his

... It is natural for geneticists and evolutionary biologists to hope that their disciplines will throw new light on the human condition ....

account is just. I agree that what we now need in sociobiology is a more cautious analysis of data, and a more careful consideration of alternative hypotheses. This will not come easily, for reasons that are as much sociological as scientific. The critique by Gould and Lewontin has had little impact on practitioners, perhaps because they were seen as hostile to the whole enterprise, and not merely to careless practise of it. Theorists like myself are understandably delighted when some set of observations seems to fit their theories. Field workers, equally understandably, are pleased if their data receive a rational explanation. The time has come, however, for editors and referees to place more emphasis on the quality of the data, and the care with which alternative explanations have been considered, and less on success in fitting the data to some particular theory. But, as Kitcher insists, the enterprise is worthwhile, and the best work is of a high standard.

What of man? Clearly. biology must have something to say. Man is an animal, and has evolved by the same processes as other animals. The debate is between those who, while accepting that man is an animal, argue that he is such a peculiar animal that evolutionary biology can have little to say about his social behaviour, and those who think that the study of human societies, just as of ant societies, must be rooted in biology. The second position Kitcher refers to as "pop sociobiology". I think this is a pity, for two reasons. First, it gives an image of superficiality and appeal to popular prejudice which, at least sometimes, is quite unfair: it is hard to imagine anyone less "pop" than Richard Alexander. Second, it gives the wrong impression of what Kitcher himself is doing: he is scrupulous about putting the best interpretation on sociobiological arguments. But I see his difficulty: we do need a term for the application of sociobiology to human beings, and I have no better one to offer. 
Kitcher's basic position is that one cannot dismiss pop sociobiology simply by asserting that it assumes genetic determinism and is therefore false, since plausible sociobiological arguments can be developed which do not assume that genes determine behaviour. There is therefore no escape from considering these arguments in detail, and to see if they stand up

... one cannot dismiss pop sociobiology simply by asserting that it assumes genetic determination and is therefore false ...

and deliver any fruit. Kitcher distinguishes two schools of pop sociobiology, those of E. O. Wilson and of Alexander. Wilson's basic argument he sees in the form of a ladder, as follows:

(i) We can plausibly argue that the members of some population, $G$, would maximize their fitness by exhibiting behaviour B.

(ii) If we observe that members of $G$ in fact do $\mathrm{B}$, we conclude that $\mathrm{B}$ became, and remains, prevalent through natural selection.

(iii) Because selection is effective only if there are genetic differences, we can conclude that there are genetic differences between current members of $G$ and their ancestors, who did not do B.

(iv) Because there are genetic differences, and because the behaviour is adaptive, the behaviour will be difficult to modify by altering the social environment.

This is a shortened version of Kitcher's reconstruction. A major part of his book consists of a step-by-step critique. Clearly, the last step is based upon the shakiest grounds: the fact that our ancestors did B in all previous environments is not proof that they will do $B$ in a wholly new one. The first three steps look more secure. Kitcher's most effective criticism here is not of the logical possibility of taking these steps, but of the ways in which they are in fact taken. For example, consider sexual behaviour. He quotes Wilson as espousing the view that evolution will lead to males that are "aggressive, hasty, fickle, and undiscriminating", and females that are "coy". But theory suggests not one evolutionary optimum, but several, and a number of our primate relatives form longterm pair bonds and show extensive male parental care. Hence there is little justification for Wilson's first step onto the ladder.

A second illegitimate way of getting on to the ladder is to apply to animals words which describe some human behaviour. For example, mallard drakes are said to "rape" ducks. Now it is true that drakes do force copulations on ducks and, by so doing, probably increase their fitness. What is the harm in calling this rape? If you are interested in ducks, rather little. but if you are interested in people, quite a lot. It implies that human rape occurs because it increases the inclusive fitness of the rapist. The contexts in which rape occurs makes this implausible. I agree that there is a danger in applying words such as "aggression", "incest", "homosexuality" and so on to animals and man alike, when the behaviours referred to may be quite different. However I do have reservations. The alternative is often to invent a turgid and incomprehensible vocabulary to describe what animals do. I remember our unsuccessful attempt to introduce the term "kleptogamy" at an ethological congress, because we feared that the AngloSaxon alternative might offend our hosts.

A few years ago, I worked through the equations in Lumsden and Wilson's Genes, Mind, and Culture and found them to be badly flawed. Kitcher has done a still more thorough job, and come to essentially the same conclusion: his chapter is entitled "The Emperor's New Equations". On three occasions Wilson has found it helpful to find a mathematical collaborator His first two were Robert MacArthur and George Oster: he was third time unlucky.

The second approach to human sociobiology, taken, for example, by Alexander, Irons, Chagnon and Dickemann, is more direct. Man is treated like any other animal. The question asked is as follows: given the social environment, do people behave so as to maximize their inclusive fitness? The answer, it is claimed, is "yes". Unlike Wilson's arguments, which seem to me generally ill-formulated and empty of content, this claim is worth taking seriously, even though it is probably false. Kitcher, attacks it on two fronts. First, he asks what proximate mechanism could possibly bring such behaviour about, since it seems to require an unconscious relationship-calculator and fitness-maximizer influencing our conscious actions. If I were Alexander, I would reply that, if the claim is true, then it is up to psychologists to discover the mechanism.

Kitcher's second line of attack is to ask whether people do in fact maximize their fitness. Here, the test case is Dickemann's account of societies practising female infanticide, and other acts not obviously contributing to fitness. Kitcher gives a careful analysis of this case. and develops a mathematical model of it suggesting that the increases in inclusive fitness that Dickemann proposes would not in fact occur. I am not sure whether he is right, but this is where the action is. This school of sociobiologists do say things about real societies that are testable; I find it hard to believe that they are right, but at least they are not vacuous.

This is an admirable book. Kitcher has the necessary background in biology, mathematics and philosophy. $\mathrm{He}$ is aware of his prejudices, and does his best to overcome them. This will not be the last word, but it is the best one yet.

John Maynard Smith is Professor in the School of Biological Sciences, University of Sussex. Falmer, Brighton BNI $9 Q G, U K$.

\section{A case of peripatetic mammaldom}

\section{David W. Macdonald}

Naturalized Mammals of the World. By Christopher Lever. Longman: 1985. Pp.487. £40. To be published in the United States late 1985/early 1986, \$79.95.

THE innocent naturalist might relish a glimpse of an elusive mammal as a glimpse of unspoilt nature - a sight that might have brought a thrill in just that place. under just those circumstances, for millennia. Surely mammals, of all creatures. with their unassailable wildness, and secretive and often nocturnal habits, remain untainted by the meddling hand of man, albeit restricted to dwindling enclaves of suitable habitat?

Naturalized Mammals of the World shatters any such illusion that wild mam-

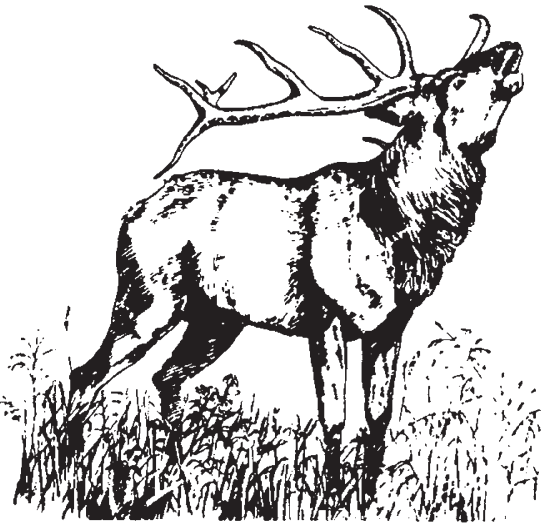

Red deer - now a New World resident

mals are where they ought to be, or rather where they used to be. The reader will not be many pages into this intriguing catalogue of mishaps before succumbing to the overwhelming impression of a peripatetic mammaldom, of which an astounding array of displaced species are wreaking biogeographical havoc. Most people could name a handful of aliens in their country - in Britain, for example, the grey squirrel and coypu - but common knowledge of the few belies the many lessnotorious species which have been deliberately (and, generally, in retrospect, misguidedly) shuffled around the globe. I got up to 67 major introductions before losing count. To qualify for the doubtful distinction of inclusion in the book, a species should have been imported from its natural range to a new country or region either deliberately or accidentally by human agency, and should currently be established in the wild in self-maintaining and self-perpetuating populations unsupported by, and independent of, man.

Apart from a succinct introductory section, and a set of useful tables and appendices, the book is made up of single. species monographs, each of which documents that species' displacement and sub- 